\title{
Senegal: Education and public declarations contribute to Tostan's
} success

Population Council

Follow this and additional works at: https://knowledgecommons.popcouncil.org/departments_sbsr-rh

Part of the Demography, Population, and Ecology Commons, Family, Life Course, and Society Commons, Gender and Sexuality Commons, International Public Health Commons, Medicine and Health Commons, Sociology of Culture Commons, and the Women's Health Commons How does access to this work benefit you? Let us know!

\section{Recommended Citation}

"Senegal: Education and public declarations contribute to Tostan's success," FRONTIERS OR Summary. Washington, DC: Population Council, 2008. 
Senegal
FGM/C

OR Summary 70

\section{Education and Public Declarations Contribute to Tostan's Success}

The Tostan program of village education effected positive changes in women's knowledge, awareness, and social standing. With the accompanying anti$F G M / C$ declaration, this model strongly influenced the initiation of abandonment of FGM/C in the Senegalese villages that received the program. However, the region's extreme poverty and lack of basic infrastructure impede full utilization of knowledge and behavior changes gained.

\section{Background}

In 1998 the nongovernmental organization Tostan implemented a village empowerment program in southern and western Senegal. Tostan's goal was to help communities, especially women, improve living and health conditions in their villages, and to mobilize villages to hold public declarations supporting the abandonment of harmful practices, particularly female genital mutilation/cutting (FGM/C) and child marriage. The program included local-language modules on hygiene, literacy and numeracy, human rights, and children's and women's health, including sexuality and harmful practices. Participating villages launched initiatives such as hygiene committees and incomegenerating projects to address village concerns. The Tostan approach resulted in declarations by numerous villages that they intended to abandon FGM/C. The approach has since been implemented more broadly in Senegal and in Burkina Faso, Guinea, and Sudan.

In 2005-6, at the request of UNICEF, the FRONTIERS Program collaborated with Macro International and the Human Development Research Centre (CDRH) in Senegal to evaluate the longterm impact of the Tostan program. This evaluation focused on the abandonment of FGM/C and child marriage by participating and non-participating villages, and on its long-term impact on daily life in participating villages. FRONTIERS conducted the qualitative research, while Macro and $\mathrm{CDRH}$ conducted the quantitative research.
The qualitative evaluation focused on the 28 villages in the regions of Thiès, Fatick, and Kolda where the Tostan program was implemented between 1996 and 2000. Researchers visited 10 villages of Type A (those that received the Tostan intervention and made declarations) and two of Type B (villages that participated in declaration ceremonies but not the education modules). Only two Type B villages could be found, as all others in the area had eventually received the Tostan intervention.

Trained interviewers conducted qualitative interviews with a total of 150 participating women, non-participating women, village and religious leaders, program facilitators, and other informants in the 12 villages.

\section{Findings}

-Qualitative and quantitative measures showed that Tostan's approach led to a significant reduction of FGM/C (see Box). While some informants suggested that the practice may be continuing in secret, most leaders and community members felt that villagers would honor their promises to abandon FGM/C.

-Uncut girls did not experience negative reactions from the community, and had no difficulty finding husbands. However - partly because of the impact of the Tostan program on FGM/C - families are now far more worried about pregnancy out of wedlock than previously. This concern-one 
of the traditional reasons for early marriage and FGM/C - needs attention if the decision to abandon is to be sustained.

\section{A quantitative change}

Findings from the quantitative study showed $30 \%$ of women had at least one circumcised daughter in the 21 Type A villages, compared to $69 \%$ in 25 comparison villages where $\mathrm{FGM} / \mathrm{C}$ was prevalent and Tostan had not worked. Among women who had at least one cut daughter, three times as many women in Type A villages (62\%) than in the comparison villages $(20 \%)$ said that they did not intend to have their daughters cut in the future (Ndiaye, Diop, and Yoder, 2007).

- The program's effect on abandonment of early marriage was limited and cannot be attributed solely to Tostan, as several organizations are conducting related interventions. The concept of early marriage was not well understood; some informants still do not feel that age 15 is too early for marriage.

- Informants reported that they had gained greater self-confidence and important knowledge from the education sessions including a much better understanding about hygiene, maternal and child health, education for girls, women's capacity for leadership, and relationships between couples.

- However, except for activities related to hygiene, village initiatives formed during the Tostan interventions did not persist after the interventions ended. Lack of systematic follow-up by Tostan, combined with poverty and the absence of basic infrastructure, prevented participating villages from making full use of the knowledge they gained. This led to frustration among some informants who said that they could not apply their education to improve their daily lives.
- Many informants believed that Tostan provided "financing" or grants to participating villages. This perception, though inaccurate (very limited financing supported gatherings for the declarations, and Tostan helped some "graduated" villages to obtain grants from other sources) can undermine Tostan's reputation if its financial role is not clarified.

\section{Utilization}

-UNICEF used the findings as a rationale for the development of a coordinated strategy for FGM/C abandonment.

\section{Policy Implications}

- The Tostan approach can lead to significant reductions in $\mathrm{FGM} / \mathrm{C}$ in participating communities. This study showed that both the education program and the public declaration are necessary elements. However, the program's focus on increasing knowledge and encouraging healthy behaviors may not, by itself, be appropriate for implementation in very poor areas. In such areas, where daily survival is the primary focus and infrastructure is weak or nonexistent, Tostan's impact on daily life was limited.

- A partnership between Tostan and other organizations, in which infrastructure improvement and poverty reduction projects with micro-credit activities follow the education program, might be tested as a way to achieve a stronger and more sustainable effect on daily life in participating communities.

- It may be necessary to develop a follow up mechanism to ensure the sustainability of changes made during the intervention.

January 2008

Source: Diop, Nafissatou J., Amadou Moreau, and Hélène Benga. 2008. "Evaluation of the long term impact of the Tostan programme on the abandonment of FGM/C and early marriage: Results from a qualitative study," FRONTIERS Final Report. Available on our website at www.popcouncil.org/frontiers or by e-mail: frontiers@popcouncil.org See also Ndiaye, Salif, Nafissatou Diop, and P. Stanley Yoder. 2007. "Évaluation à long terme du programme de Tostan au Sénégal: Régions de Kolda, Thiès et Fatick." Calverton, MD: Macro International.

This publication is made possible by the generous support of the American people through the United States Agency for International Development (USAID) under the terms of Cooperative Agreement No. HRN-A-00-98-00012-00. The contents are the responsibility of the FRONTIERS Program and do not necessarily reflect the views of USAID or the United States Government. 